\title{
Perspective Piece \\ SARS-CoV-2 Shedding from Asymptomatic Patients: Contribution of Potential Extrapulmonary Tissue Reservoirs
}

\author{
Raj Kalkeri, ${ }^{1 \star}$ Scott Goebel, ${ }^{1}$ and Guru Dutt Sharma ${ }^{2}$ \\ ${ }^{1}$ Southern Research, Frederick, Maryland; ${ }^{2}$ College of Optometry, Western University of Health Sciences, Pomona, California
}

\begin{abstract}
The ongoing pandemic COVID-19, caused by SARS-CoV-2, has already resulted in more than 3 million cases and more than 200,000 deaths globally. Significant clinical presentations of COVID-19 include respiratory symptoms and pneumonia. In a minority of patients, extrapulmonary organs (central nervous system, eyes, heart, and gut) are affected, with detection of viral RNA in bodily secretions (stool, tears, and saliva). Infection of such extrapulmonary organs may serve as a reservoir for SARS-CoV-2, representing a potential source of viral shedding after the cessation of respiratory symptoms in recovered patients or in asymptomatic individuals. It is extremely important to understand this phenomenon, as individuals with intermittent virus shedding could be falsely identified as reinfected and may benefit from ongoing antiviral treatment. The potential of SARS-CoV-2 infection to rapidly disseminate and infect extrapulmonary organs is likely mediated through the nonstructural and accessory proteins of SARS-CoV-2, which act as ligands for host cells, and through evasion of host immune responses. The focus of this perspective is the extrapulmonary tissues affected by SARS-CoV-2 and the potential implications of their involvement for disease pathogenesis and the development of medical countermeasures.
\end{abstract}

\section{INTRODUCTION}

The current pandemic COVID-19 caused by SARS-CoV- 2 is rapidly spreading across the globe, with more than 3 million infections and more than 200,000 deaths worldwide. The receptor of SARS-CoV-2, angiotensin converting enzyme 2 (ACE2), is expressed in the lungs, heart, kidneys, intestines, brain, eyes, and testicles. ${ }^{1,2}$ Infection of these extrapulmonary organs (eyes, gastrointestinal tract, and brain) ${ }^{3}$ has been reported. Viral shedding in asymptomatic individuals and recovered patients after the cessation of respiratory symptoms ${ }^{4,5}$ has been documented. Although SARS-CoV-2 positivity of recovered patients may be interpreted as reinfection, failure to reinfect monkeys in the laboratory setting ${ }^{6}$ argues against the possibility of reinfection and suggests the likelihood of extrapulmonary reservoirs in the infected individuals. Considering this possibility, this perspective is focused on extrapulmonary organs affected by SARS-CoV-2 and the implications of their involvement for disease transmission, clinical management strategies, and medical countermeasure discovery and development.

SARS-CoV-2 and extrapulmonary tissues and organs. In addition to the primary respiratory route of infection via droplets or contact with fomites, the expression of ACE2 in aqueous humor ${ }^{7}$ and neural tissue of the retina ${ }^{8}$ suggest a potential role of transmission via an ocular route. The ocular reservoir can harbor low viral load, even before transmission to other organs such as the throat or lungs, as $75 \%$ of tears drain into the inferior meatus of the nasal cavity and to the back of the throat. ${ }^{9}$ Red eyes, conjunctivitis, conjunctival hyperemia, chemosis, epiphora, or increased secretions are observed in a minority of patients, along with detectable SARS-CoV-2 RNA in tears. ${ }^{10,11}$ Although viral RNA is infrequently detected $(1-5 \%)$ in tears, ocular manifestations are relatively common in COVID-19-positive patients (10-30\%). This could be due in

*Address correspondence to Raj Kalkeri, Southern Research, 431 Aviation Way, Frederick, MD 21701-4789. E-mail: rkalkeri@ southernresearch.org part to timing of sample collection, fluctuations in virus shedding, and variability in testing methods. Standardized approaches for sample collection along with more sensitive testing methods may yield more robust data. Additional research is needed to confirm the temporal correlation between conjunctivitis and viral shedding in COVID-19 patients.

The gastrointestinal tract is also affected by SARS-CoV-2. Diarrhea and shedding of SARS-CoV-2 in stool are reported in the literature. ${ }^{12,13}$ Currently, transmission through the fecaloral route is not documented. However, it remains a possibility considering the detection of SARS-CoV-2 RNA in wastewater and municipal sewage. ${ }^{14}$ Fecal shedding also increases the risk of creating a new intermittent animal reservoir and emergence of new viral strains through recombination, which could serve as starting points of new outbreaks.

Neurological manifestations (headache, loss of taste and smell, dizziness, impaired consciousness, and epilepsy) are reported in some COVID-19 patients. ${ }^{15}$ SARS-CoV-2 RNA was also detected in the cerebrospinal fluid of a patient diagnosed with COVID-19 and viral encephalitis. ${ }^{16}$ It is postulated that coronaviruses can enter the central nervous system (CNS) via olfactory nerve, blood circulation, and neuronal pathways, leading to neurological abnormalities and symptoms. ${ }^{17}$ Liver, kidney, and heart abnormalities are also observed in COVID-19 patients, ${ }^{18,19}$ and although SARS-CoV-2 RNA is not reported in these tissues after autopsy, the detection of viral RNA in the liver of the hamster model ${ }^{20}$ suggests the infection of these organs in patients.

Although SARS-CoV-2 RNA is detected in the blood (1\% of patients), ${ }^{3}$ at present, it is unknown if the virus is shed in breast milk, semen, or vaginal fluid. Extrapulmonary complications in COVID-19 patients include diarrhea (gastrointestinal tract), confusion (CNS), hepatic, and renal injury. ${ }^{21}$ Some of these complications may also be due to compromised pulmonary function. Extrapulmonary tissues affected by SARS-CoV-2 are listed in Table 1. Currently, it is unknown if SARS-CoV-2 can replicate in non-respiratory tissues (eyes, liver, and CNS) to produce infectious virus. However, SARS virus has been shown to replicate in human kidney (HEK293) and hepatic 
TABLE 1

Extrapulmonary tissues affected by SARS-CoV-2

\begin{tabular}{ll}
\hline \multicolumn{1}{c}{ Organ } & \multicolumn{1}{c}{ Clinical finding } \\
\hline Lungs $^{38}$ & Acute respiratory distress syndrome \\
Eyes $^{39}$ & Conjunctivitis \\
Liver $^{40,41}$ & Liver injury \\
Systemic circulation (blood) $^{3}$ & Thrombosis \\
Kidney $^{19,18}$ & Renal injury \\
Brain $\mathrm{CNS}^{1,42}$ & CNS symptoms \\
Gl tract $^{13,12}$ & Diarrhea \\
\hline CNS $=$ central nervous system; $\mathrm{Gl}=$ gastrointestinal.
\end{tabular}

(Huh7 and HepG2) ${ }^{22}$ cell lines and detected in the liver and brain of patients. ${ }^{23,24}$ Experimental infection of primary tissue cells with SARS-CoV-2 and longitudinal studies in infected patients and animal models can promote a greater understanding of the role of these tissues in the infection.

Ocular and CNS tissues are considered immune-privileged sites. ${ }^{25,26}$ For other pathogens such as Cytomegalovirus (CMV), Zika virus, Ebola virus, and other beta coronaviruses (Table 2), these organs have been shown to serve as reservoirs, facilitating viral persistence. ${ }^{27}$ Many COVID-19 patients test positive even after discharge from the hospital. ${ }^{28,29}$ In one report, SARS-CoV-2 RNA was detected up to 60 days after the onset of symptoms and 36 days after complete resolution of symptoms in the patient's nasopharyngeal and/or oropharyngeal swabs. ${ }^{30}$ Another study reported undetectable viral load on days 21 and 22 after symptom onset in oropharyngeal saliva samples of a COVID-19 patient, followed by viral RNA detection on days 23 and 24, without any detectable virus for the next 5 days. ${ }^{31}$ Taken together, reports of prolonged incubation periods where virus is shed from asymptomatic infected persons ${ }^{4}$ or recovered patients several days after disease symptoms with an intermittent period of shedding, ${ }^{31}$ along with the detection of SARS-CoV-2 in the extrapulmonary tissues, strongly suggest the presence of extrapulmonary SARS-CoV-2 tissue reservoirs. These extrapulmonary virus tissue reservoirs in infected patients may also explain the highly variable incubation period associated with the onset of symptoms after an initial exposure as well as the duration of time for complete viral clearance.

Role of SARS-CoV-2 proteins in immune evasion. Nonstructural proteins (NSP1, 3, and 16) and accessory proteins (ORF 3a, 6, and 9b) of SARS-CoV-2 are thought to play a role in the evasion of host immune responses (Table 3). A recent report also predicted a potential role of SARS-CoV-2 NSP5 and NSP13 interfering with the host immune response. ${ }^{32}$ Considering the substantial sequence similarity of more than $80 \%$ between SARS and SARS-CoV-2 proteins (Table 3), it is quite possible that SARS-CoV-2 can also escape the host

TABLE 2

Extrapulmonary tissue reservoirs of other coronaviruses

\begin{tabular}{|c|c|c|}
\hline Organ & Species & Coronaviruses \\
\hline Brain & $\begin{array}{l}\text { Mice } \\
\text { Mice } \\
\text { Human } \\
\text { Mice }\end{array}$ & $\begin{array}{l}\text { SARS-CoV }^{43} \\
\text { MERS-CoV } \\
\text { HCoV-229E } \\
\text { HCoV-OC43 } \\
\text { HCo }\end{array}$ \\
\hline Liver & $\begin{array}{l}\text { Human } \\
\text { Mice }\end{array}$ & $\begin{array}{l}\text { SARS-CoV }{ }^{23} \\
\text { Mouse hepatitis Virus (MHV-A59) }\end{array}$ \\
\hline $\begin{array}{l}\text { Kidneys } \\
\text { Gl tract }\end{array}$ & $\begin{array}{l}\text { Human } \\
\text { Human }\end{array}$ & $\begin{array}{l}\text { Endemic Balkan nephropathy virus }{ }^{48} \\
\text { HCoV-HKU } 1^{49}\end{array}$ \\
\hline
\end{tabular}

TABLE 3

SARS-CoV-2 proteins, homology to SARS, and proposed impact on host immunity

\begin{tabular}{|c|c|c|}
\hline $\begin{array}{c}\text { Protein } \\
\text { (SARS-CoV-2) }\end{array}$ & $\begin{array}{l}\text { Homology with } \\
\text { SARS (\%) }\end{array}$ & Mechanism of immune suppression in SARS \\
\hline NSP1 & 91.1 & $\begin{array}{l}\text { Host RNA degradation and immune } \\
\text { suppression }\end{array}$ \\
\hline NSP3 & 86.5 & $\begin{array}{l}\text { Papain-like protease, deubiquitination, } \\
\text { and host IRF3 function inhibition }{ }^{52,53}\end{array}$ \\
\hline NSP16 & 98.0 & $\begin{array}{l}2^{\prime} \text { O Methyltransferase. Cap methylation } \\
\text { is necessary to evade immune } \\
\text { response }\end{array}$ \\
\hline ORF 3a & 85.1 & Downregulation of type $1 \mathrm{IFN}$ receptor ${ }^{55}$ \\
\hline ORF 6 & 85.7 & Inhibition of STAT1 function ${ }^{56}$ \\
\hline ORF 9b & 84.7 & $\begin{array}{l}\text { Degradation of MAVS, TRAF3, and } \\
\text { TRAF } 6^{57}\end{array}$ \\
\hline
\end{tabular}

NSP $=$ nonstructural protein; ORE =accessory protein.

immune response using similar mechanisms in nonrespiratory tissues such as the liver and kidneys.

Implications of SARS-CoV-2 infection in extrapulmonary tissues. The presence of extrapulmonary tissue reservoirs enhances the risk of organ malfunction, such as abnormal liver or kidney functions and impaired nervous system, leading to exacerbated disease complications and delayed recovery time in COVID-19 patients. Tissue reservoirs in immunocompromised patients are a major concern as the virus could spread to the respiratory system at an opportune time, exerting a more aggressive clinical course. Reports of continued or delayed virus shedding up to 36 days after cessation of symptoms ${ }^{30,33}$ suggest that longer term monitoring of recovered COVID-19 patients and improved virus containment strategies will be required to mitigate further community transmission. Currently, the amount of virus present in the extrapulmonary reservoirs relative to the amount of virus shed, such as in aerosol droplets, is unknown. As different viral loads have been observed in various bodily fluids (saliva, tears, feces, throat, or nasal discharge), longitudinal testing of "paired samples" collected from these different sites may be needed.

The proportion of asymptomatic carriers potentially shedding the virus from both pulmonary and extrapulmonary virus reservoirs is estimated to be between $17.9 \%{ }^{34}$ and $30.8 \%,{ }^{35}$ suggesting the importance of population-based screening using sensitive and robust assays. For other viral diseases such as measles and norovirus infection, viral transmission from asymptomatic carriers is well documented. ${ }^{36,37}$ Hence, global harmonization of the sensitivity and robustness of SARS-CoV-2 detection kits and screening of populations at risk might ensure identification of asymptomatic carriers of infection.

Potential antiviral drugs against SARS-CoV-2 may need to demonstrate bioavailability in extrapulmonary tissue reservoirs outside of the lungs, raising concerns of adverse events. Achieving efficacious levels of therapeutics in some of these tissues may be challenging because of the presence of blood-brain and blood-retina barriers. Vaccine and antiviral candidates may also need to demonstrate efficacy in the prevention of tissue reservoirs, which could introduce additional stringency requirements for clinical trials.

Development of appropriate animal models can address some of these questions. Golden Syrian hamsters infected with SARS-CoV-2 exhibited contact transmission, weight loss, lung damage, intestinal mucosal inflammation, lymphoid 
atrophy, myocardial degenerative changes, and expression of viral nucleocapsid in lungs and intestines. ${ }^{20}$ Interestingly, viral RNA could be detected in extrapulmonary tissues such as the liver, heart, spleen, kidneys, brain, and salivary glands, confirming the extrapulmonary manifestation of SARS-CoV-2 disease. Although hamsters could be a cost-effective animal model for SARS-CoV-2, lack of hamster-specific immunological reagents and unknown utility for testing medical countermeasures could limit their role in SARS-CoV-2 preclinical studies. Rhesus monkeys have been successfully infected with SARS-CoV-2. ${ }^{6}$ Viral replication was observed in extrapulmonary tissues (gut, spinal cord, heart, skeletal muscles, and bladder). Reexposure of previously infected monkeys elicited no signs of viral replication in extrapulmonary tissues, suggesting it could be a useful animal model to study SARS-CoV-2 tissue reservoirs and efficacy of vaccines. However, it is also important to note the importance of inoculation dose, age of animals, and route of challenge (ocular, intranasal, or oral) in the development and utility of animal models to address different research questions.

Several scientific questions remain to be addressed to fully understand COVID-19 clinical disease progression, including potential differences in extrapulmonary tissue infections with respect to age or ethnicity. It will also be necessary to consider the kinetics and duration of viral shedding, which could be impacted by viral bio-distribution within and among different tissue reservoirs. In addition, the role of host immune responses and the expression of host factors must be considered as dynamic forces in driving genotypic or virologic differences among viral quasi-species isolated from different reservoirs. The identification of non-respiratory tissue reservoirs of SARS-CoV-2 suggests that further studies are needed to address implications for COVID-19 disease progression, effects on extrapulmonary tissues harboring the virus, and development of optimal medical countermeasures and disease management strategies.

Received April 11, 2020. Accepted for publication May 5, 2020.

Published online May 13, 2020.

Acknowledgments: We thank Carol Lackman-Smith for her critical review and help with the manuscript. Publication charges for this article were waived due to the ongoing pandemic of COVID-19.

Authors' addresses: Raj Kalkeri and Scott Goebel, Drug Development, Southern Research, Frederick, MD, E-mails: rkalkeri@southernresearch. org and sgoebel@southernresearch.org. Guru Dutt Sharma, College of Optometry, Western University of Health Sciences, Pomona, CA, E-mail: gsharma@westernu.edu.

This is an open-access article distributed under the terms of the Creative Commons Attribution (CC-BY) License, which permits unrestricted use, distribution, and reproduction in any medium, provided the original author and source are credited.

\section{REFERENCES}

1. Baig AM, Khaleeq A, Ali U, Syeda H, 2020. Evidence of the COVID19 virus targeting the CNS: tissue distribution, host-virus interaction, and proposed neurotropic mechanisms. ACS Chem Neurosci 11: 995-998.

2. SunX, Zhang X, Chen X, Chen L, Deng C, Zou X, Liu W, Yu H, 2020. The Infection Evidence of SARS-COV-2 in Ocular Surface: $A$ Single-Center Cross-Sectional Study. Available at: https:// www.medrxiv.org/content/10.1101/2020.02.26.20027938v1. Accessed May 5, 2020.

3. Wang W, Xu Y, Gao R, Lu R, Han K, Wu G, Tan W, 2020. Detection of SARS-CoV-2 in different types of clinical specimens. JAMA e203786. Available at: https://jamanetwork.com/journals/ jama/fullarticle/2762997.

4. Rothe $\mathrm{C}$ et al., 2020. Transmission of 2019-nCoV infection from an asymptomatic contact in Germany. $N$ Engl $J$ Med 382: 970-971.

5. Zhou X, Li Y, Li T, Zhang W, 2020. Follow-up of the asymptomatic patients with SARS-CoV-2 infection. Clin Microbiol Infect. Available at: https://www.clinicalmicrobiologyandinfection.com/ article/S1198-743X(20)30169-5/pdf.

6. Bao L et al., 2020. Reinfection could not occur in SARS-CoV-2 infected rhesus macaques. bioRxiv. Available at: https:// www.biorxiv.org/content/10.1101/2020.03.13.990226v2.

7. Holappa M, Valjakka J, Vaajanen A, 2015. Angiotensin (1-7) and ACE2, "the hot spots" of renin-angiotensin system, detected in the human aqueous humor. Open Ophthalmol J 9: 28-32.

8. Senanayake P, Drazba J, Shadrach K, Milsted A, RunggerBrandle E, Nishiyama K, Miura SI, Karnik S, Sears JE, Hollyfield JG, 2007. Angiotensin II and its receptor subtypes in the human retina. Invest Ophthalmol Vis Sci 48: 3301-3311.

9. AnnRemington L, 2012. Clinical anatomy and physiology of the visual system. Remington LA, ed. Ocular Adnexa and Lacrimal System. Oxford, UK: Butterworth-Heinemann, 159-181.

10. Xia J, Tong J, Liu M, Shen Y, Guo D, 2020. Evaluation of coronavirus in tears and conjunctival secretions of patients with SARS-CoV-2 infection. J Med Virol. Available at: https:// onlinelibrary.wiley.com/doi/full/10.1002/jmv.25725.

11. Wu P, Duan F, Luo C, Liu Q, Qu X, Liang L, Wu K, 2020. Characteristics of ocular findings of patients with coronavirus disease 2019 (COVID-19) in Hubei province, China. JAMA Ophthalmol e201291. Available at: https://jamanetwork.com/ journals/jamaophthalmology/fullarticle/2764083.

12. Yeo C, Kaushal S, Yeo D, 2020. Enteric involvement of coronaviruses: is faecal-oral transmission of SARS-CoV-2 possible? Lancet Gastroenterol Hepatol 5: 335-337.

13. Hosoda T, Sakamoto M, Shimizu H, Okabe N, 2020. SARS-CoV-2 enterocolitis with persisting to excrete the virus for about two weeks after recovering from diarrhea: a case report. Infect Control Hosp Epidemiol 1: 1-4.

14. Lodder W, de Roda Husman AM, 2020. SARS-CoV-2 in wastewater: potential health risk, but also data source. Lancet Gastroenterol Hepatol. Available at: https://www.thelancet. com/pdfs/journals/langas/PIIS2468-1253(20)30087-X.pdf.

15. Mao L et al., 2020. Neurological manifestations of hospitalized patients with COVID-19 in Wuhan, China: a retrospective case series study. medRxiv. Available at: https://www.medrxiv.org/ content/10.1101/2020.02.22.20026500v1.

16. Moriguchi T et al., 2020. A first case of meningitis/encephalitis associated with SARS-coronavirus-2. Int J Infect Dis 94: 55-58.

17. Wu Y, Xu X, Chen Z, Duan J, Hashimoto K, Yang L, Liu C, Yang C, 2020. Nervous system involvement after infection with COVID-19 and other coronaviruses. Brain Behav Immun. Available at: https://www.sciencedirect.com/science/article/ pii/S0889159120303573?via\%3Dihub.

18. Rismanbaf A, Zarei S, 2020. Liver and kidney injuries in COVID-19 and their effects on drug therapy; a letter to editor. Arch Acad Emerg Med 8: e17.

19. Chen T et al., 2020. Clinical characteristics of 113 deceased patients with coronavirus disease 2019: retrospective study. BMJ 368: $\mathrm{m} 1091$.

20. Chan JF et al., 2020. Simulation of the clinical and pathological manifestations of coronavirus disease 2019 (COVID-19) in golden syrian hamster model: implications for disease pathogenesis and transmissibility. Clin Infect Dis. Available at: https:// academic.oup.com/cid/advance-article/doi/10.1093/cid/ciaa325/ 5811871.

21. Guan WJ et al., 2020. Clinical characteristics of coronavirus disease 2019 in China. N Engl J Med 382: 1708-1720.

22. Kaye M, 2006. SARS-associated coronavirus replication in cell lines. Emerg Infect Dis 12: 128-133.

23. Chau TN et al., 2004. SARS-associated viral hepatitis caused by a novel coronavirus: report of three cases. Hepatology 39: 302-310.

24. Xu J et al., 2005. Detection of severe acute respiratory syndrome coronavirus in the brain: potential role of the chemokine mig in pathogenesis. Clin Infect Dis 41: 1089-1096. 
25. Barker CF, Billingham RE, 1977. Immunologically privileged sites. Adv Immunol 25: 1-54.

26. Carson MJ, Doose JM, Melchior B, Schmid CD, Ploix CC, 2006. CNS immune privilege: hiding in plain sight. Immunol Rev 213: 48-65.

27. Kalkeri R, Murthy KK, 2017. Zika virus reservoirs: implications for transmission, future outbreaks, drug vaccine development. F1000Res 6: 1850.

28. Lan L, Xu D, Ye G, Xia C, Wang S, Li Y, Xu H, 2020. Positive RTPCR test results in patients recovered from COVID-19. JAMA 323: 1502-1503.

29. Hu Z et al., 2020. Clinical characteristics of 24 asymptomatic infections with COVID-19 screened among close contacts in Nanjing, China. Sci China Life Sci 63: 706-711.

30. Li J, Zhang L, Liu B, Song D, 2020. Case report: viral shedding for 60 Days in a woman with novel coronavirus disease (COVID19). Am J Trop Med Hyg 102: 1210-1213.

31. To KK et al., 2020. Temporal profiles of viral load in posterior oropharyngeal saliva samples and serum antibody responses during infection by SARS-CoV-2: an observational cohort study. Lancet Infect Dis 20: 565-574.

32. Gordon DE et al., 2020. A SARS-CoV-2-human protein-protein interaction map reveals drug targets and potential drugrepurposing. bioRxiv. Available at: https://www.biorxiv.org/ content/10.1101/2020.03.22.002386v3.

33. Bai Y, Yao L, Wei T, Tian F, Jin DY, Chen L, Wang M, 2020. Presumed asymptomatic carrier transmission of COVID-19. JAMA 323: 1406-1407.

34. Mizumoto K, Kagaya K, Zarebski A, Chowell G, 2020. Estimating the asymptomatic proportion of coronavirus disease 2019 (COVID-19) cases on board the diamond princess cruise ship, Yokohama, Japan, 2020. Euro Surveill 25: 2000180.

35. Nishiura $\mathrm{H}$ et al., 2020. Estimation of the asymptomatic ratio of novel coronavirus infections (COVID-19). Int J Infect Dis 94: 154-155.

36. Miura F, Matsuyama R, Nishiura H, 2018. Estimating the asymptomatic ratio of norovirus infection during foodborne outbreaks with laboratory testing in Japan. $J$ Epidemiol 28: 382-387.

37. Mizumoto K, Kobayashi T, Chowell G, 2018. Transmission potential of modified measles during an outbreak, Japan, MarchMay 2018. Euro Surveill 23: 1800239.

38. Goh KJ, Choong MC, Cheong EH, Kalimuddin S, Duu Wen S, Phua GC, Chan KS, Haja Mohideen S, 2020. Rapid progression to acute respiratory distress syndrome: review of current understanding of critical illness from COVID-19 infection. Ann Acad Med Singapore 49: 1-9.

39. Seah I, Agrawal R, 2020. Can the coronavirus disease 2019 (COVID-19) affect the eyes? A review of coronaviruses and ocular implications in humans and animals. Ocul Immunol Inflamm 28: 391-395.

40. Zhang C, Shi L, Wang FS, 2020. Liver injury in COVID-19: management and challenges. Lancet Gastroenterol Hepatol 5: 428-430.

41. Xu L, Liu J, Lu M, Yang D, Zheng X, 2020. Liver injury during highly pathogenic human coronavirus infections. Liver Int 40: 998-1004.

42. Li YC, Bai WZ, Hashikawa T, 2020. The neuroinvasive potential of SARS-CoV2 may play a role in the respiratory failure of COVID-19 patients. J Med Virol. Available at: https:// onlinelibrary.wiley.com/doi/full/10.1002/jmv.25728.
43. Glass WG, Subbarao K, Murphy B, Murphy PM, 2004. Mechanisms of host defense following severe acute respiratory syndrome-coronavirus (SARS-CoV) pulmonary infection of mice. J Immunol 173: 4030-4039.

44. Li K, Wohlford-Lenane C, Perlman S, Zhao J, Jewell AK, Reznikov LR, Gibson-Corley KN, Meyerholz DK, McCray PB Jr., 2016. Middle east respiratory syndrome coronavirus causes multiple organ damage and Lethal disease in mice transgenic for human dipeptidyl peptidase 4. J Infect Dis 213: 712-722.

45. Talbot PJ, Ekande S, Cashman NR, Mounir S, Stewart JN, 1993. Neurotropism of human coronavirus 229E. Adv Exp Med Biol 342: 339-346.

46. Dube M, Le Coupanec A, Wong AHM, Rini JM, Desforges M, Talbot PJ, 2018. Axonal transport enables neuron-to-neuron propagation of human coronavirus OC43. J Virol 92: e00404-18.

47. Hirano N, Murakami T, Taguchi F, Fujiwara K, Matumoto M, 1981. Comparison of mouse hepatitis virus strains for pathogenicity in weanling mice infected by various routes. Arch Virol 70: 69-73.

48. Uzelac-Keserovic B, Spasic P, Bojanic N, Dimitrijevic J, Lako B, Lepsanovic Z, Kuljic-Kapulica N, Vasic D, Apostolov K, 1999. Isolation of a coronavirus from kidney biopsies of endemic Balkan nephropathy patients. Nephron 81: 141-145.

49. Bouvier M et al., 2018. Species-specific clinical characteristics of human coronavirus infection among otherwise healthy adolescents and adults. Influenza Other Respir Viruses 12: 299-303.

50. Kamitani W, Narayanan K, Huang C, Lokugamage K, Ikegami T, Ito $\mathrm{N}$, Kubo H, Makino S, 2006. Severe acute respiratory syndrome coronavirus nsp1 protein suppresses host gene expression by promoting host mRNA degradation. Proc Natl Acad Sci USA 103: 12885-12890.

51. Narayanan K, Huang C, Lokugamage K, Kamitani W, Ikegami T, Tseng CT, Makino S, 2008. Severe acute respiratory syndrome coronavirus nsp1 suppresses host gene expression, including that of type I interferon, in infected cells. J Virol 82: 4471-4479.

52. Barretto N, Jukneliene D, Ratia K, Chen Z, Mesecar AD, Baker SC, 2005. The papain-like protease of severe acute respiratory syndrome coronavirus has deubiquitinating activity. J Virol 79: 15189-15198.

53. Fehr AR, Channappanavar R, Jankevicius G, Fett C, Zhao J, Athmer J, Meyerholz DK, Ahel I, Perlman S, 2016. The conserved coronavirus macrodomain promotes virulence and suppresses the innate immune response during severe acute respiratory syndrome coronavirus infection. $m B$ Bio 7: e01721.

54. Menachery VD, Yount BL Jr., Josset L, Gralinski LE, Scobey T, Agnihothram S, Katze MG, Baric RS, 2014. Attenuation and restoration of severe acute respiratory syndrome coronavirus mutant lacking 2'-o-methyltransferase activity. $J$ Virol 88: 4251-4264.

55. Minakshi R, Padhan K, Rani M, Khan N, Ahmad F, Jameel S, 2009. The SARS coronavirus $3 a$ protein causes endoplasmic reticulum stress and induces ligand-independent downregulation of the type 1 interferon receptor. PLoS One 4: e8342.

56. Frieman M, Heise M, Baric R, 2008. SARS coronavirus and innate immunity. Virus Res 133: 101-112.

57. Shi CS, Qi HY, Boularan C, Huang NN, Abu-Asab M, Shelhamer JH, Kehrl JH, 2014. SARS-coronavirus open reading frame-9b suppresses innate immunity by targeting mitochondria and the MAVS/TRAF3/TRAF6 signalosome. J Immunol 193: 3080-3089. 